\title{
Effect of Surface Wetting on Grinding Characteristics of Wheat
}

\author{
P. R. Davara ${ }^{1 *}$, N. C. Thumar $^{1}$, J. J. Limbasiya ${ }^{1}$, H. V. Agravat $^{1}$ and V. P. Sangani ${ }^{1}$ \\ Department of Processing and Food Engineering, College of Agricultural Engineering and Technology, Junagadh \\ Agricultural University, Junagadh- 362001 \\ Email: pareshdavara@yahoo.com
}

\begin{abstract}
Wheat is the most important mainly due to its use in the flour production. An experiment was conducted to study the feasibility of evaporative water cooled grinding for wheat flour production. Wheat was mixed with water $(0 \%, 3 \%, 6 \%$ and $9 \% \mathrm{w} / \mathrm{w})$ and grinded immediately using domestic hammer mill before the surface water penetrated into the grain. The different grinding characteristics were studied for the grinding operation. This process resulted in cooling since the evaporating particles carried away the heat generated inside the grinding mill resulting in decrease of the temperature of the system. The temperature during grinding was found to be decreased by $11^{\circ} \mathrm{C}$ under for the sample wetted with $9 \%(\mathrm{w} / \mathrm{w})$ of water as compared to conventional grinding. No sieve clogging was observed during evaporative water cooled grinding. Grinding time was observed to be increased by $155 \mathrm{sec}$ for the evaporative water cooled ground sample. This study revealed that the evaporative water cooled grinding method can be effectively used for avoiding the rise in temperature during grinding in order to preserve the quality of wheat.
\end{abstract}

Keywords : Wheat, grinding, evaporative water cooling, flour

\section{Introduction}

Wheat milling is the most important unit process in wheat processing. The milling methods and milling parameters depend on the direction of wheat use [4]. The two predominant techniques for grinding whole grain flours are stone and roller mills [7]. Stone mills are the oldest attrition mills used for making whole grain flours, which simultaneously use compression, shear, and abrasion to grind wheat kernels between two stones [9]. The process of roller milling involves separation of the endosperm from the bran and germ followed by gradual size reduction of endosperm [15]. Hammer mill utilize impact loading to break down larger-sized particles into smaller-sized particles [1].

Grinding is the most power consuming operation. Only $1 \%$ of the energy imparted into the material is utilized during grinding in loosening the bond between particles, whereas almost $99 \%$ of input energy is dissipated as heat, raising the temperature of the ground product [2]. Stone mills generate considerable heat due to friction. This can result in considerable damage to starch, protein, and unsaturated fatty acids in comparison with other milling techniques [12]. During grinding of spices, the temperature of a product rises to a level in the range of 42 to $95{ }^{\circ} \mathrm{C}$ [13], [14]. The problem is further complicated by rancidity dangers arising from the cracking of fat molecules. Cracked fat molecules split into free fatty acids which in turn develop rancidity in the product. The cell damage produced in grinding further has an adverse effect on the protein, amino acids, and vitamins [5]. Jefferes and Rubenthaler (1977) found that as mill temperature increased due to friction and use, flour yield decreased. Thus, thermal damage is one of the main limitations of the conventional milling process [2].

Malkin and Guo (2007) suggested that a better product could be obtained by reducing the temperature of the two rubbing surfaces. The temperature rise of the product can be minimized to some extent by circulating cold air or water around the grinder. But this technique is not sufficient enough to significantly reduce the temperature rise of the product.

The application of water in the form of small droplets on the surface of the material will not cause to increase in the products internal moisture content. But the water will be retained only on the surface and will start to evaporate as soon as it gets the energy. Evaporation results in cooling since the evaporating particles carry away the thermal energy resulting in decrease of the temperature of the system [8]. Bandra et al. (2014) had reported the promising result for grinding of chilli using evaporative water cooling method in comparison to conventional grinding method. They reported the lower 
temperature $\left(36 \pm 1.5{ }^{\circ} \mathrm{C}\right)$ of the evaporative water cooled ground chilli, which recorded upto $\left(58 \pm 2.65{ }^{\circ} \mathrm{C}\right)$ in conventionally ground chilli. No any information is available for grinding of wheat under evaporative water cooled condition. Considering all these facts, the project was undertaken to study the feasibility of using evaporative water cooled (EWC) grinding for production of wheat flour.

\section{$2 \quad$ Materials and Methods}

\subsection{Raw material}

The wheat grains required for conducting the research work were obtained from the Wheat Research Station of Junagadh Agricultural University, Junagadh. The variety of wheat was Lok-1. The wheat grains were cleaned manually to remove all foreign matters such as dust, dirt, stones, chaff, insect eaten, damaged, and broken grains.

\subsection{Grinding Mill}

The domestic hammer mill consisted of rotating hammer having running diameter of $19.5 \mathrm{~cm}$ fitted inside the grinding chamber with a grooved surface from the internal side was adopted for grinding of wheat. It was equipped with a temperature sensor fitted inside the grinding chamber which was further attached with digital temperature indicator fixed outside the grinding mill to record the temperature inside the grinding chamber during grinding of wheat. The regular sieve size, i.e. 25 mesh was selected for grinding of wheat.

\subsection{Grinding of Wheat}

Randomly obtained $1 \mathrm{~kg}$ wheat grain sample from the stock was used for evaporative water cooled grinding process. The selected sample was prepared by mixing it with water at four different levels $(0 \%$, $3 \%, 6 \%$, and $9 \%$ ). The sample was mixed thoroughly and fed immediately into the hopper of grinding mill. Grinding was then carried out before the surface water penetrated into the grain. Another sample with $1 \mathrm{~kg}$ of wheat grain was ground conventionally without mixing of water using the same hammer mill and sieved to compare it with wheat flour sample obtained with evaporative water cooled grinding.

\subsection{Grinding Time}

The grinding time per unit mass of grain was recorded using digital stopwatch by taking the time interval between feeding of wheat grains and completion of grinding. It was recorded in seconds.

\subsection{Grinding Temperature}

The temperature inside the grinding mill during grinding of wheat was recorded from digital temperature indicator fixed outside the grinding mill. The temperature was recorded at every 1 min interval to study the temperature profile during the grinding. The temperature was recorded in terms of ${ }^{\circ} \mathrm{C}$.

\subsection{Sieve Clogging}

Sieve clogging was studied by taking the ratio of number of openings clogged with respect to total number of openings in the sieve. The brush was moved on the sieve surface to clean the sieve by removing the flour deposited on sieve surface. The openings which could not be opened after brushing were only considered as a clogged opening.

\section{7 $\quad$ Statistical Analysis}

All the experiments in this study were conducted five times and the mean values were reported. Statistical analysis was done to study the effect of selected process parameter like mixed water quantity 
on dependent parameters by Completely Randomized Design (simple CRD) by using Microsoft Office Excel 2007 [11]. The results of evaporative cooled grinded wheat flour were compared with the flour grinded through conventional method, i.e. without addition of water. All the treatments were compared at $5 \%$ level of significance using the Critical Difference test (Microsoft Office Excel 2007). The Analysis of Variance (ANOVA), Standard Error of difference (SEd), Standard Error of mean (SEm) and Critical Difference (CD) for dependent parameter were tabulated and the level of significance was reported.

\section{$3 \quad$ Results and Discussion}

The various grinding characteristics for grinding of wheat at different mixed water level are tabularized in Table 1.

Table 1. Grinding and flour characteristics of wheat for different treatments.

\begin{tabular}{llll}
\hline Treatment & Grinding time $(\mathrm{sec})$ & $\begin{array}{l}\text { Grinding } \\
\text { temperature }\left({ }^{\circ} \mathrm{C}\right)\end{array}$ & Sieve clogging (\%) \\
\hline $\mathrm{W} 0$ & 603 & 78 & 0.00 \\
\hline $\mathrm{W} 1$ & 613 & 75 & 0.00 \\
\hline $\mathrm{W} 2$ & 670 & 68 & 0.00 \\
\hline $\mathrm{W} 3$ & 758 & 67 & 0.00 \\
\hline S.Em. \pm & 1.465 & 0.485 & -- \\
\hline C.D. at 5 $\%$ & 4.391 & 1.453 & -- \\
\hline C.V. $\%$ & 0.495 & 1.508 & -- \\
\hline
\end{tabular}

\subsection{Grinding Time}

The graphical comparison of average grinding time of wheat grinded at different mixed water quantity is shown in Fig.1. The average grinding time of wheat was significantly lowest for the treatment $\mathrm{W}_{0}$ (without mixing of water) whereas significantly highest in for the treatment $\mathrm{W}_{3}(9 \%$ mixed water quantity) (Table 1$)$. This showed that the grinding time was increased as the surface moisture increased. For the smaller quantity of mixing water, i.e. control and $3 \%$, the increase in grinding time was smaller $(15 \mathrm{sec})$. But, it was found to be increased noticeably as the quantity of mixed water was increased from $3 \%$ to $6 \%$ and from $6 \%$ to $9 \%$. It was observed to be increased by 56 sec and $88 \mathrm{sec}$ as the quantity of mixed water was increased from $3 \%$ to $6 \%$ and from $6 \%$ to $9 \%$, respectively. Overall, the mixing of water up to its maximum selected level (9\%) increased the grinding time by maximum of 155 sec in comparison to control treatment. The increase in grinding time in surface wetted wheat samples can be attributed to the adhesiveness increased in the flour due to absorption of moisture by flour particles. During grinding, the whole wheat grain was converted into flour which is highly hygroscopic in nature. Hence, the rate of absorption of moisture by flour particles was increased and grinding efficiency was decreased resulted in increase of grinding time.

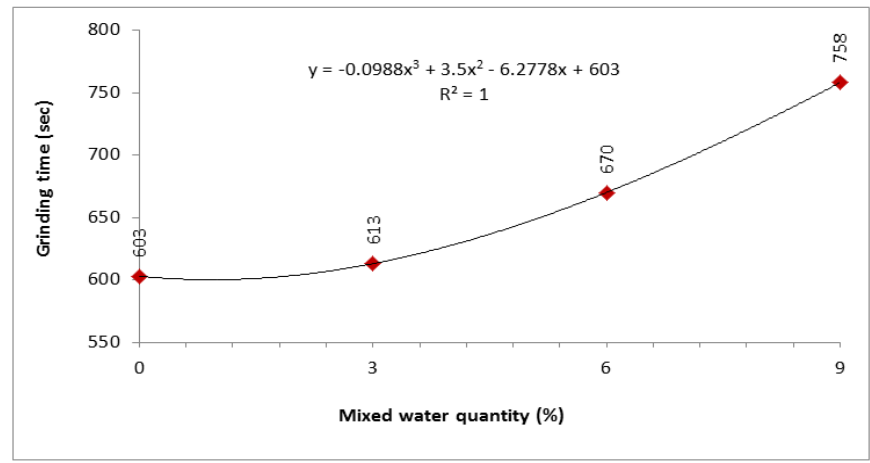

Figure 1. Effect of mixed water quantity on grinding time of wheat. 


\subsection{Grinding Temperature}

The grinding temperature ranged from 67 to $78{ }^{\circ} \mathrm{C}$. The maximum temperature of mill at the end of grinding $\left(78^{\circ} \mathrm{C}\right)$ was observed in the treatment $\mathrm{W}_{0}$, i.e. without mixing of water whereas minimum of it $\left(67{ }^{\circ} \mathrm{C}\right.$ ) was found for the treatment $\mathrm{W}_{3}$, i.e. $9 \%$ mixed water quantity (Table 1). Fig. 2 shows the effect of mixed water quantity on grinding temperature. Fig. 2 revealed that the addition of surface moisture decreased the grinding temperature. At smaller level of mixing water quantity, i.e. control and $3 \%$, the decrease in grinding temperature was smaller $\left(3^{\circ} \mathrm{C}\right)$. The rate of decrease of grinding temperature was higher $\left(7^{\circ} \mathrm{C}\right)$ when the mixed water quantity was increased from 3 to $6 \%$. But, the same was lower $\left(1{ }^{\circ} \mathrm{C}\right)$ when the mixed water quantity was further increased from 6 to $9 \%$. From the results, it could be concluded that the addition of surface moisture up to $9 \%$ can reduce the grinding temperature maximum of $11{ }^{\circ} \mathrm{C}$ as compared to control treatment. The decrease in grinding temperature in surface wetted wheat samples can be attributed to the loss of heat due to evaporation of added water. Heat generated during size reduction steered to increase the grinding temperature in control treatment while heat generated was reduced in evaporative water cooled grinding due to the added water as sensible and latent heat. Bandara et al. (2015) also reported the reduction in the grinding temperature while grinded by evaporative cooled grinding method.

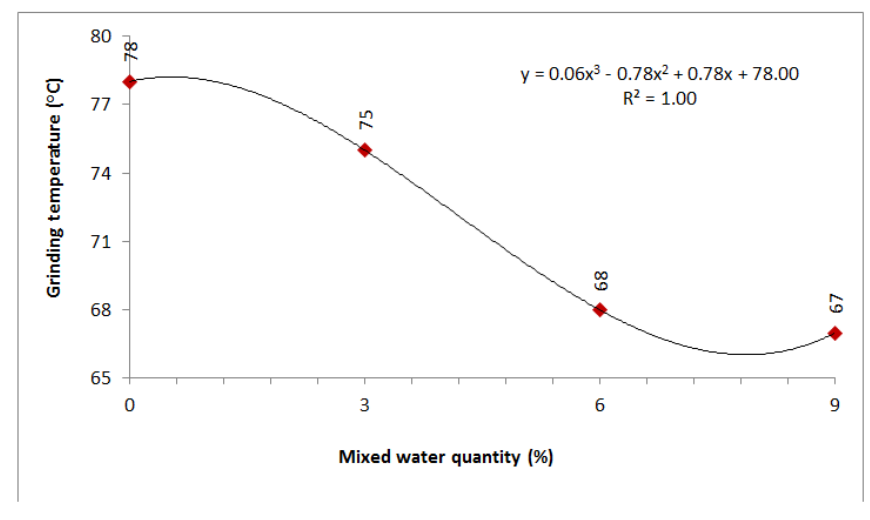

Figure 2. Effect of mixed water quantity on grinding temperature at the end of grinding.

\subsection{Temperature Profile of Mill during Grinding}

The data on temperature inside the grinding mill at different time intervals for different treatments is graphically presented in the Fig. 3. Initially, before start of the grinding, the temperature inside the grinding chamber was set equally at normal room temperature $\left(28{ }^{\circ} \mathrm{C}\right)$ for all the treatments. From the Fig. 3, it can be observed that the temperature inside the grinding chamber was increased continuously for all the treatments as the time of grinding advanced. There was a negligible difference in the grinding temperature among the different treatments during initial period of 3 min. But, later on, when the time of grinding exceeded beyond $4 \mathrm{~min}$, significant difference in the grinding temperature among the different treatments was observed. The treatment $\mathrm{W}_{3}$, i.e. $9 \%$ of mixed water quantity, reported the lowest rise in the grinding temperature at the end of grinding. In surface wetted wheat grains, sufficient amount of water was there to absorb the heat produced during size reduction. The process of evaporative water cooling was more successfully performed in these treatments. This resulted in small amount of rise in the grinding temperature of the surface wetted wheat grains in comparison to control treatment at the end of grinding. Based on the favourable results obtained in the treatment $\mathrm{W}_{3}$, the trendline was generated and regression equation was predicted for this treatment as given in the Fig. 3 . 


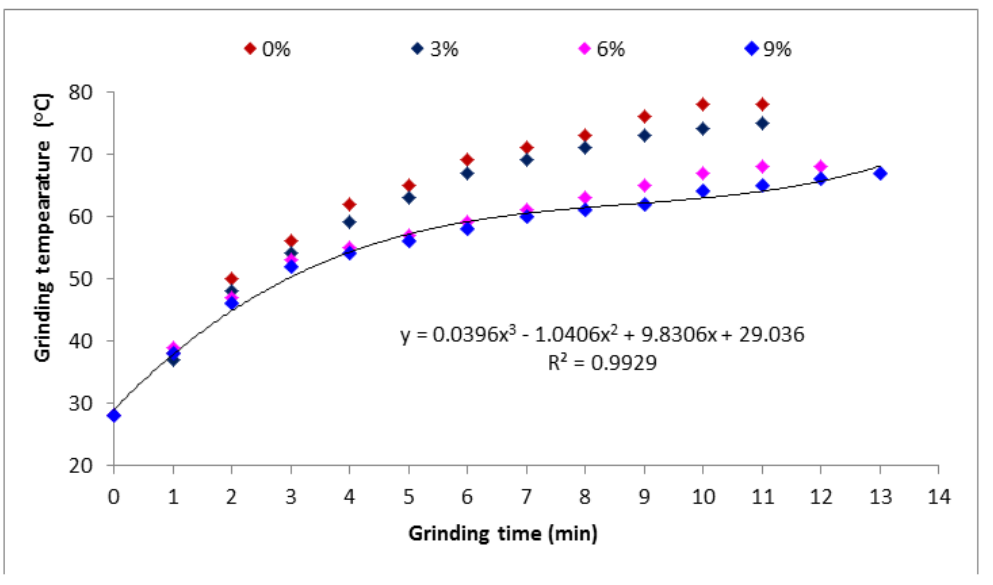

Figure 3. Temperature profile of mill during grinding.

\subsection{Sieve Clogging}

No sieve clogging was observed in any of the treatments (Table 1). This indicated that addition of surface water to the wheat grain did not affect the flour flowing ability and due to that all flour particles were easily passed out from the holes of the sieve. However, certain deposition was observed over the sieve surface after the grinding which could be removed easily by brushing over the surface.

\section{Conclusions}

The feasibility study of addition of surface water to wheat grain during grinding was carried out. The effect of wheat grain surface wetting on grinding time, grinding temperature, temperature profile during grinding and sieve clogging was studied. An increase in surface moisture of wheat grains has a stronger effect on the decrease in the grinding temperature. The grinding time was increased by maximum of 155 sec as the surface moisture increased up to $9 \%$. The addition of surface moisture could successfully reduce the elevation of temperature during grinding. The wheat grain wetted by adding $9 \%$ water was able to reduce temperature by $11{ }^{\circ} \mathrm{C}$ as compared to control treatment at the end of grinding. No sieve clogging was observed during grinding of any of the surface wetted wheat grain samples. The positive effect of surface wetting of wheat grain suggested its usefulness in controlling the rise of temperature inside the grinding mill.

\section{References}

1. Austin, L. "A treatment of impact breakage particles." Powder Technology, vol. 126, no. 1, pp. 85-90, 2002.

2. Bandara, D.M.S.P., Amarathunga, K.S.P., Thilakaratne, B. M. K. S., Dissanayake, T. M. R., Dharmasena, D. A. N. and Fernando, A. J. Feasibility study of evaporative water cooled (EWC) grinding methodfor chilli (Capsicum annum L.).Tropical Agricultural Research, vol. 26, no. 1, pp. 189-194, 2014.

3. Bandara, D.M.S.P., Amarathunga, K. S. P., Thilakaratne, B. M. K. S., Dissanayake, T. M. R., Dharmasena, D. A. N. and Fernando, A. J. "Use of evaporative water cooling (EWC) in grinding chili."Engineer, vol. 48, no. 3, pp. 13-17, 2015.

4. Dziki, D., Pietrzak, G. C., Biernacka, B., Jończyk, K., Różyło, R. and Gładyszewska, B. "The grinding energy as an indicator of wheat milling value".Teka. Commission of Motorization and Energetics in Agriculture, vol. 12, no. 1, pp. 29-33, 2012.

5. Hanser, W. F. "Reduction of cereal grains to flour." Unites States Patent No. US3399838A. Accessed at https://www.google.ch/patents/US3399838, 1968.

6. Jeffers, H. C. and Rubenthaler, G. L. "Effect of roll temperature on flour yield with the brabenderquadrumat experimental mills." Cereal Chemistry, vol. 54, pp. 1018-1025, 1977. 
7. Kent, N. L. and Evers, A. D. "Technology of Cereals."Elsevier : Tarrytown, NY, 1994.

8. Ketterle, W. and Van Druten, N. J. "Evaporative cooling of trapped atoms." Advances in Atomic, Molecular and Optical Physics, vol. 37, pp. 181-236. DOI: 10.1016/S1049-250X(08)60101-9, 1995.

9. Kihlberg, I., Johansson, L., Kohler, A. and Risvik, E. Sensory qualities of whole wheat pan bread - influence of farming system, milling, and baking technique. Journal of Cereal Science, vol. 39, pp. 67-84, 2004.

10.Malkin, S. and Guo, C. "Thermal Analysis of Grinding." Annals of the CIRP. Connecticut, USA. Science Direct, vol. 56, no. 2, pp. 760-782, 2007.

11.Panse, V. G. and Sukhatme, P.V. "Statistical Methods for Agricultural Workers", Fourth Editions. ICAR, New Delhi, 1958.

12.Prabhasankar, P. and Rao, P. H. "Effect of different milling methods on chemical composition of whole wheat flour." European Journal of Food Research and Technology, vol. 213, pp. 465-469, 2001.

13.Pruthi, J. S. and Misra, B. D. "Physical, chemical and microbiological changes in curry powders during drying, milling and mixing operation." Spices Bull. vol. 3, pp. 9-13, 1963.

14.Singh, K. K. and Goswami, T. K. "Design of a cryogenic grinding system for spices." Journal of Food Engineering, vol. 39, pp. 359-368, 1999.

15.Ziegler, E. and Greer, E. N. "Wheat flour milling." In: Wheat (Pomeranz, Y. Ed.), 1971. 